\title{
They Didn't Believe Her Pain: My Education in Interpersonal Violence
}

\author{
Amelia Goodfellow, $M D^{1}$ \\ Curtis Bone MD, MHS ${ }^{2,3}$ \\ Lillian Gelberg $M D, M S P H^{4,5}$ \\ 'Naval Medical Center San Diego, \\ San Diego, California \\ ${ }^{2}$ Yale University School of Medicine, \\ New Haven, Connecticut \\ ${ }^{3}$ VA Connecticut Healthcare System, \\ West Haven, Connecticut \\ ${ }^{4}$ Department of Family Medicine, David \\ Geffen School of Medicine at UCLA, \\ Los Angeles, California \\ ${ }^{5}$ Fielding School of Public Health, Univer- \\ sity of California, Los Angeles (UCLA), \\ Los Angeles, California
}

Conflicts of interest: authors report none.

\section{CORRESPONDING AUTHOR:}

Amelia Goodfellow, MD

801 A Street, Apt. 1710

San Diego, CA 92101

amelia.goodfellow@gmail.com

\begin{abstract}
In my first year of medical school, I began to care for patients who were survivors of interpersonal violence. As I transitioned from didactics to clinical experiences, I was struck by how common the hidden threads of physical and sexual violence were in my patients' stories of chronic pain, depression, and poor health outcomes. Their symptoms often seemed intangible and challenging to treat, unable to fit neatly into typical diagnostic and therapeutic algorithms. In response, I saw clinicians become frustrated and dissatisfied with their ability to treat these patients. Better care for survivors may begin simply with believing our patients' pain.
\end{abstract}

Ann Fam Med 2018;16:361-363. https://doi.org/10.1370/afm.2266.

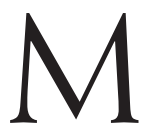
onday morning, first year of medical school: our problem-based learning (PBL) group files into the classroom to meet our patient. It's early in the year, and I (A.G.) can hardly believe I'm actually going to be a doctor. Just 6 months ago, I was working as a counselor and case manager at a county public health HIV/STD department. While I'm enjoying the complexity of clinical medicine, I can't shake the feeling that sometimes we get caught up in the "facts" of a disease and lose sight of the person behind it. I find myself missing the intimacy of conversations with my former clients as they gave voice to their histories of trauma and hopes for the future. Though sterile, PBL offers something both new and familiar: I love sifting through cases like a detective, listening for what is and is not said to arrive at a diagnosis.

Our physician facilitator has recorded a real patient from her Veterans Affairs pain clinic for today's case. I imagined an older male veteran, maybe coming in for a decades-old injury that's acting up again. The video clicks on. A middle-aged woman sits stiffly in a chair, leaning away from the interviewer with her back unusually straight. She is meticulously dressed, but appears tired and doesn't smile when the interviewer greets her. When she adjusts her hair, the movement is short and jerky, painful. Her voice is sandpapery, like she hasn't been getting enough sleep. She is here, we learn, for evaluation a few weeks after being assaulted at a nightclub. "I was knocked down, then dragged by my hair," she says, looking down at her lap.

I winced involuntarily, my brow furrowing in sympathy as she described the violent attack. "I can barely turn my head," she said, demonstrating. "I can't do anything. I can't even put my hair up."

I became uncomfortably aware of a shred of uncertainty in the back of my mind. Wasn't her hair expertly done? Weren't her nails painstakingly manicured? She certainly didn't fit the stereotyped image of chronic pain I'd imagined at the start of the session. I felt ashamed: not only had I assumed our patient would look and act a certain way, but I'd caught myself beginning to invalidate her pain because she wasn't experiencing it the way I thought she would.

The doctor in the video was now gently examining the patient's range of motion. The woman flinched away at the lightest touch. "Please, stop! 
That's enough," she pleaded. Her pain was extraordinary, clearly out of proportion to the exam. As she continued to gasp and cry out, snickers escaped from some of my classmates.

I felt my cheeks redden. They didn't believe her, and they didn't believe her pain. I sat uncomfortably silent as the interview continued. Our patient was now describing that this last assault was just one in a long history of physical abuse by her ex-husband. "I feel tired all the time," she said slowly. "Everything hurts, and nothing, none of these doctors, have been making it better." Her expression was vacant, like she lacked the energy to even be sad or frustrated. "I just want some relief."

We stopped the video to brainstorm a differential diagnosis.

"Fibromyalgia," offered one of my classmates.

"Acute on chronic cervical injury."

"Malingering?" said the last.

This was a reasonable differential, but it felt like something crucial was being lost. I was discouraged to see the patient's pain so quickly dismissed. It seemed like we were focused on identifying her physical injury while totally ignoring the clear psychological burden her pain imparted. At the same time, I could sense the temptation to fit her complaints quickly into a neat box. After all, if so many doctors had failed to help her in the past, could her complaints really be fixed?

I wondered how I would even begin to help this patient in a 15 -minute office visit. Someday, tired and overworked, would I feel frustration instead of compassion when a patient like her came to see me? Were we already starting to view a chief complaint of chronic pain as just a euphemism for "crazy"?

Two years later, in clinic at a busy public hospital, my questions were tested. The resident and I went to see our patient, a 40-year old, heavyset woman. She was perched nervously on the edge of the exam table, folding and unfolding her hands, a large bag of prescriptions and medical records at her side, and began to describe profound pain that prevented her from working or even doing house chores. My resident took a hurried history, barely able to look up from the computer. "Will you finish off the interview for me?" she asked, her hand already on the doorknob.

Alone with the patient, the interview quickly veered away from her physical complaints. I learned that her pain began shortly after a bad car accident a few years prior, and she'd been plagued by anxiety and insomnia ever since. Tears filled her eyes as she alluded to a difficult home life and physical abuse by a past partner. After years of partial workups and halfhearted pain regimens, I was seeing firsthand how little the medical system had done to help her find relief. How many more are there like her, I wondered-and what can be done to help?

Interpersonal violence, whether sexual, physical, emotional, family, or community in nature, is estimated to affect more than one-quarter of women and one-tenth of men in the United States each year. ${ }^{1}$ Further, victimization in childhood and early adult life places survivors at elevated risk for revictimization, precipitating a vicious cycle of escape from one's abuser into the arms of another. Survivors of violence interact with the health care system more frequently, have more medical comorbidities, are more likely to have a diagnosis of depression, anxiety, or posttraumatic stress disorder (PTSD), and are at higher risk for substance use than nonsurvivors. ${ }^{2,3}$ Importantly, they are also more likely to carry diagnoses of chronic pain disorder and somatization., ${ }^{4,5}$

At the neurophysiologic level, studies have shown higher norepinephrine concentrations in victims of abuse, creating a new "set point" for stress. ${ }^{5}$ Patients with depression and a history of abuse also have a diminished ability to bind serotonin in key areas of the brain responsible for mood regulation, which may affect successful treatment of associated mood disorders in this group. ${ }^{6,7}$ Moreover, substance $\mathrm{P}$, which mediates nociceptive, stressful, and nauseating stimuli, is elevated in the cerebrospinal fluid of patients with chronic pain complaints such as headache, chronic nausea, irritable bowel syndrome, and fibromyalgia $^{8}$ - all medical complaints which occur more frequently in victims of violence. Dysregulation of the hypothalamic-pituitary-adrenal axis in survivors of abuse attenuates the stress response, producing disproportionate responses to "non-threats" while lessening the response to repeated stressors like abuse. ${ }^{9}$

Chronic stress profoundly impacts the body's cardiovascular, endocrine, and immune systems, increasing the risk of atherosclerosis, diabetes, and infection. Even when controlling for traditional risk factors, diseases like obesity, heart disease, asthma, and even certain cancers are more likely to occur in survivors of violence. ${ }^{10,11}$ The link between medical disease and history of abuse, however, is often obscured by the way these patients present: survivors rarely volunteer their histories of violence, often making somatic and nonspecific complaints the only tip-off to a deeper problem. ${ }^{12}$ Both my patient from PBL and my clinic patient readily disclosed past interpersonal violence-but both were frustrated, and desperate for a solution. How many times do we see patients with these challenging diagnoses and never recognize their history of abuse? How often are we missing a critical window for meaningful intervention?

We as physicians are just beginning to understand how to support patients through recovery after inter- 
personal violence. The first step is reducing our own barriers to screening for this occult condition: many clinicians incorrectly believe the prevalence of interpersonal violence is low, and that they do not possess strategies to help survivors of abuse once identified. ${ }^{13}$ We can begin to address this gap by building assessment of interpersonal violence into the social history with brief, validated, high-sensitivity screening tools such as the Abuse Assessment Screen (AAS) or the STaT questionnaire. ${ }^{14-16}$ If a patient screens positive for interpersonal violence, tools such as the Secondary Survey give clinicians a scripted pathway to communicate support, validate concerns, and collect more information about the patient's current level of safety. ${ }^{17}$ While mandated reporting laws vary by state, and available resources vary by clinical setting, at minimum, national resources can be provided at the point of care. ${ }^{18}$ Lastly, any clinician can become an advocate for additional training in detection and care for survivors of violence in their clinical practice.

Now with a longer white coat and a pager that rarely rests, I can empathize with my resident from clinic. In the midst of overwhelming clinical and administrative duties, it is easy to rush past patients' subtle signals of distress. I am hopeful that I will maintain the energy, resolve, and presence of mind to open the door to more complex encounters with those in need of this care. I hope that sensitive inquiry into history of interpersonal violence and referral to treatment will become more commonly taught and practiced skills in medical training. But first, as a beginning, I hope we can simply agree to believe our patients' pain.

To read or post commentaries in response to this article, see it online at http://www.AnnFamMed.org/content/16/4/361.

Key words: intimate partner violence; physical abuse; domestic violence

Submitted October 5, 2017; submitted, revised, March 7, 2018; accepted April 4, 2018.

\section{References}

1. National Center for Injury Prevention and Control. Costs of Intimate Partner Violence Against Women in the United States. Atlanta,GA: Centers for Disease Control and Prevention; 2003. https://www.cdc.gov/ violenceprevention/pdf/IPVBook-a.pdf.

2. Geracioti TD Jr, Carpenter LL, Owens MJ, et al. Elevated cerebrospinal fluid substance $p$ concentrations in posttraumatic stress disorder and major depression. Am J Psychiatry. 2006;163(4):637-643.

3. Kremer I, Orbach I, Rosenbloom T. Mental Pain and Suicidal Tendencies in Sexual and Physical Abuse Victims. Arch Suicide Res. 2017;21(2):307-321.
4. Dickinson WP, Dickinson LM, deGruy FV, et al. The somatization in primary care study: a tale of three diagnoses. Gen Hosp Psychiatry. 2003;25(1):1-7.

5. Keeshin BR, Cronholm PF, Strawn JR. Physiologic changes associated with violence and abuse exposure: an examination of related medical conditions. Trauma Violence Abuse. 2012;13(1):41-56.

6. As-Sanie S, Clevenger LA, Geisser ME, Williams DA, Roth RS. History of abuse and its relationship to pain experience and depression in women with chronic pelvic pain. Am J Obstet Gynecol. 2014; 210(4):317.e1-317.e8.

7. Rinne T, Westenberg HG, den Boer JA, van den Brink W. Serotonergic blunting to meta-chlorophenylpiperazine (m-CPP) highly correlates with sustained childhood abuse in impulsive and autoaggressive female borderline patients. Biol Psychiatry. 2000;47(6):548-556.

8. Hemsing N, Greaves L, Poole N, Schmidt R. Misuse of prescription opioid medication among women: a scoping review. Pain Res Manag. 2016:1754195.

9. Trickett PK, Noll JG, Susman EJ, Shenk CE, Putnam FW. Attenuation of cortisol across development for victims of sexual abuse. Dev Psychopathol. 2010;22(1):165-175.

10. Dong M, Giles WH, Felitti VJ, et al. Insights into causal pathways for ischemic heart disease: adverse childhood experiences study. Circulation. 2004;110(13):1761-1766.

11. Felitti VJ, Anda RF, Nordenberg D, et al. Relationship of childhood abuse and household dysfunction to many of the leading causes of death in adults. The Adverse Childhood Experiences (ACE) Study. Am J Prev Med. 1998;14(4):245-258.

12. McCall-Hosenfeld JS, Winter M, Heeren T, Liebschutz JM. The association of interpersonal trauma with somatic symptom severity in a primary care population with chronic pain: exploring the role of gender and the mental health sequelae of trauma. J Psychosom Res. 2014;77(3):196-204.

13. Sugg NK, Thompson RS, Thompson DC, Maiuro R, Rivara FP. Domestic violence and primary care. Attitudes, practices, and beliefs. Arch Fam Med. 1999;8(4):301-306.

14. Basile KC, Hertz MF, Back SE. Intimate Partner Violence and Sexual Violence Victimization Assessment Instruments for Use in Healthcare Settings: Version 1. Atlanta, GA: Centers for Disease Control and Prevention, National Center for Injury Prevention and Control; 2007. https: //www.cdc.gov/violenceprevention/pdf/ipv/ipvandsvscreening.pdf.

15. Paranjape A, Liebschutz J. STaT: a three-question screen for intimate partner violence. J Womens Health (Larchmt). 2003;12(3): 233-239.

16. Soeken KL, McFarlane J, Parker B, Lominack MC. The abuse assessment screen: a clinical instrument to measure frequency, severity, and perpetrator of abuse against women. In: Campbell JC, ed. Sage Series on Violence Against Women. Empowering Survivors of Abuse: Health Care for Battered Women and Their Children. Thousand Oaks, CA: Sage Publications; 1998:195-203.

17. The Family Violence Prevention Fund. National Consensus Guidelines on Identifying and Responding to Domestic Violence Victimization in Health Care Settings. Published Sep 2002. Revised 2004. https://www.futureswithoutviolence.org/ national-consensus-guidelines-heath-care-settings.

18. Cronholm PF, Fogarty CT, Ambuel B, Harrison SL. Intimate partner violence. Am Fam Physician. 2011;83(10):1165-1172. 